\title{
EDUCAÇÃO AMBIENTAL EM UMA ESCOLA DE ENSINO MÉDIO COMO FERRAMENTA PARA CONHECIMENTO DO PASSIVO AMBIENTAL
}

\author{
Eder Wolney da Roza Gonçalves ${ }^{1}$, Djalma Dias da Silveira² \\ ${ }^{1}$ Especialista em Educação Ambiental pela UFSM. \\ ${ }^{2}$ Professor, Doutor, Orientador pela UFSM.
}

\section{RESUMO}

O presente artigo é baseado na monografia intitulada EDUCAÇÃO AMBIENTAL EM UMA ESCOLA DE ENSINO MÉDIO COMO FERRAMENTA PARA CONHECIMENTO DO PASSIVO AMBIENTAL, DO CURSO DE Educação Ambiental da Universidade Federal de Santa Maria, apresentada no dia 16 de dezembro de 2011. Esta monografia trabalhou a Educação Ambiental em dois momentos distintos: no primeiro momento buscou-se o conhecimento técnico sobre passivo ambiental e, através de uma pesquisa não estruturada a situação do município nesta questão. No segundo momento procurou-se mostrar uma forma de aplicação da Educação Ambiental dentro do ensino da Matemática. Para tanto, foi escolhida uma proposta dos Parâmetros Curriculares Nacionais (PCN's) e da Política Nacional de Educação Ambiental (Lei no 9.795 de 27/04/99) que utiliza a temática ambiental de forma transversal com a disciplina de Matemática. Isto se deu através da elaboração de um projeto de pesquisa, realizada por alunos do ensino médio da escola estadual de ensino médio Engenheiro Parobé, abordando o tema da produção, ou não, de um passivo ambiental na indústria, na saúde e na gestão pública do município. Assim, pretende-se estabelecer uma ligação entre as funções e a álgebra da Matemática Elementar numa tentativa de mostrar um caminho para a educação ambiental. Com levantamentos de dados sobre o passivo ambiental construíram-se gráficos, tabelas e relações percentuais para uma análise quantitativa e para visualização do comportamento da taxa de produção do lixo e dos recursos destinados a solução deste problema. A Matemática contextualizando com a temática ambiental é uma forma não só de dinamizar as aulas tornando-as mais interligadas e relacionadas com o contexto ambiental local e global, mas também como forma de estudar os problemas ambientais e ecológicos despertando a consciência discente para o uso racional dos recursos naturais, construindo assim um modelo de educação voltada à cidadania socioambiental.

Palavras chaves: Passivo ambiental; projeto de pesquisa; matemática; Educação Ambiental.

\section{ABSTRACT}

This article is referring to a monograph titled ENVIRONMENTAL EDUCATION IN A HIGH SCHOOL AS A TOOL FOR KNOWLEDGE OF ENVIRONMENTAL LIABILITIES, environmental education course at the Universidade Federal de Santa Maria, presented on December 16, 2011. This Environmental Education monograph worked at two distinct times: at first it was tried the technical knowledge about environmental liabilities, and by searching unstructured situation of the Municipality on this issue. In the second phase sought to show how to implement an environmental education into the teaching of mathematics. To this, we dealt with a proposal of 
the National Curriculum Parameters (PCN's) and the National Policy on Environmental Education (Law No. 9795 of April 27, 1999, Brazil) to use environmental issues across the board with Mathematics, by a research project conducted by students from high school in a state school, addressing the subject of production, or not, of an environmental liability in industry, health and governance of the municipality. We intend to establish a link between the functions and algebra of Elementary Mathematics in an attempt to show the way for environmental education. With survey data on the environmental liabilities, were constructed graphs; tables and percentage relationships for a quantitative analysis and visualization of the behavior of the rate of production of waste and resources to solve this problem. Mathematics contextualizing with the environment is not only a way of stimulating classes, making them more interconnected and related to the local and global environmental context, but also as a way to study the environmental and ecological problems raising awareness for students use natural resources, this way building a model of education focus on social and environmental citizenship.

Key words: environmental liabilities; research project; mathematic; environment education.

\section{INTRODUÇÃO}

As atividades econômicas e seus efeitos sobre o meio ambiente são questões mundialmente discutidas. A mudança de paradigmas na relação homem-natureza teve início no Renascimento com o antropocentrismo, passando pela revolução industrial, pelo liberalismo, culminando no século XX com a exploração desenfreada dos recursos naturais. Para evitar, compensar ou minimizar seus impactos ambientais negativos, as atividades econômicas potencialmente poluidoras são atualmente objetos de legislação específica, disciplinadoras de procedimentos tecnológicos e operacionais capazes de eliminar ou reduzir poluentes. Uma área contaminada é conceituada como sendo a localidade onde determinadas substancias ocorrem em concentração acima de padrões de referência e onde uma avaliação indica que representa ou poderá representar, incluindo alteração de uso/ocupação do solo, risco imediato ou de médio/longo prazo para a saúde humana ou meio ambiente. Uma área contaminada quando não conta com um projeto/plano e um programa para eliminar as pendências ambientais existentes, representa para a instituição particular ou pública um passivo ambiental. Uma empresa ou gestão municipal tem passivo ambiental quando ela agride, de algum modo e/ou ação, o meio ambiente.

A educação que o indivíduo necessitava era adquirida por meio da família, da comunidade, seus costumes e hábitos. A formação do homem é bem mais complexa do que aprender os conhecimentos acadêmicos ou familiares. Ele deve extrapolar seu individual e chegar ao social, onde exerce e sofre influencia, podendo compreender e atuar em seu entorno social, convertendo problemas em oportunidades. A constituição federal reconhece a importância da educação escolar para além do ensino fundamental e médio onde crianças e adolescentes aumentem a capacidade de discernimento e criticidade com sua comunidade local, regional e planetária, construirão uma identidade cidadã, sendo protagonistas e responsáveis por suas ações. Dessa forma o professor deixa de ser mero repassador de seu conhecimento e se conscientiza que é sujeito crítico e participativo do processo educativo. 


\section{OBJETIVOS}

O objetivo deste trabalho foi o de proporcionar aos alunos da área de matemática, da 2a e 3a série do ensino médio da E. E. E. M. Engenheiro Parobé a oportunidade, através da realização de um projeto de pesquisa, concebido a partir de pressupostos da Educação Ambiental, conhecer a realidade de sua cidade, no que conta sobre a existência, ou não, de passivo ambiental gerado por uma possível falha na coleta de lixo comum doméstico, lixo industrial/químico e lixo hospitalar, usando para isso a matemática e a educação ambiental como ferramentas transversais.

Como objetivo secundário tem-se:

Objetivo 1. O autor, reconhecer através de uma pesquisa bibliográfica algumas normas e leis (federais, estaduais, municipais) sobre legislação e sobre passivo ambiental, verificando, também, junto à Administração Pública, via secretaria do Meio ambiente do município de Parobé, a existência, ou não, de passivo ambiental na atual gestão e o tratamento tomado para sanar e evitar este problema.

Objetivo 2. A criação de um Blog em que serão postados arquivos que contenham informações sobre passivo ambiental, que contenham as informações colhidas pelo autor junto à administração pública e arquivos que ajudarão os alunos a escreverem e apresentarem este projeto, como elementos da metodologia e exemplos de citações. Os problemas ambientais podem ser gradativamente diminuídos com a sensibilização dos educandos a partir de iniciativas dentro da própria escola e dentro do ensino da matemática fundamental ou média, e daí para a comunidade.

\section{METODOLOGIA}

Basicamente o projeto se desenvolveu ao longo do tempo, através de pesquisa bibliográfica, para a compreensão das leis ambientais e para a coleta de dados nacionais, regionais e municipais sobre o meio ambiente. Santos (1999) afirma que pesquisa bibliográfica é baseada no conjunto de materiais escritos ou gravados, mecânica ou eletronicamente, que contém informações já elaboradas e publicadas por outros autores.

As buscas realizadas em sites de pesquisas como o scielo, Dominiopúblico, Ufsm/educacaoambientaladistancia, biblioteca Ufrgs, sites governamentais, etc., centraram-se em obter conhecimentos sobre passivo ambiental. Concomitantemente a estas buscas, foram realizadas buscas em literatura especializada em leis, orientações e códigos no âmbito federal, estadual e municipal que tratam do meio ambiente, da educação ambiental e das resoluções tomadas frente à existência de passivos ambientais.

No dia oito de outubro de 2010 aconteceu à entrevista não estruturada com o secretário Municipal do Meio Ambiente, com ênfase à existência ou não de passivo ambiental na administração pública e nas empresas privadas da cidade, e além de responder a todas as questões, acrescentou informações valiosas e que passariam despercebidas não fosse a sua intervenção. Após terem sidos coletados, esses dados foram estudados, analisados, dispostos no Blog para serem lidos e utilizados pelos alunos na construção do projeto de pesquisa. 0 desenvolvimento deste trabalho se embasa de duas principais maneiras. Primeiramente o 
professor realiza uma pesquisa bibliográfica sobre o tema proposto, usa da forma descritiva, através de normas e leis que regulam o impacto ambiental e sua transformação ou não em passivo ambiental. Para complementar esta pesquisa o professor realiza uma entrevista não estruturada com o Secretário do Meio Ambiente da cidade de Parobé, RS, considerando as respostas dadas pelo entrevistado e sua opinião sobre o caso, com a finalidade de adquirir conhecimento qualitativo sobre o meio ambiente e sobre a realidade municipal, para então repassar estes dados aos seus alunos.

Os alunos envolvidos neste projeto realizaram uma pesquisa de campo, ora exploratória, ora descritiva, realizando entrevistas não estruturadas com profissionais envolvidos com a realidade ambiental do município sobre o tema proposto e coletarão dados, sem a interferência do pesquisador, de forma quantitativa, para então transformar esta pesquisa em gráficos, tabelas e dados estatísticos, para que possam ser expostos na escola

\section{Caracterização das turmas que realizaram o projeto}

Para a realização do projeto de pesquisa foram escolhidas as nove turmas em que o autor é professor. Sendo elas dispostas desta maneira: 05 (cinco) turmas do $2^{\circ}$ ano do ensino médio, duas diurnas e três noturnas; 04 (quatro) turmas do $3^{\circ}$ ano do ensino médio, duas diurnas e duas noturnas, sendo elas, respectivamente, conhecidas por 222, 223, 224, 225, 226, 231, 231, 233 e 234 . As turmas são compostas em média de 24 alunos, gerando assim, uma média, de 04 (quatro) trabalhos por turma, visto que o número de componentes era determinado, porém, não era fixo.

O projeto: Dos dias 06 (seis) ao dia 10 (dez) de junho do corrente ano, foi proposto aos alunos do $2^{\circ}$ e $3^{\circ}$ ano do ensino médio da E.E.E.M. Engenheiro Parobé, Parobé, RS, que formassem grupos de até quatro alunos para realizarem, de forma transversal entre a área da matemática e o meio ambiente, um projeto de pesquisa e que escolhessem, aleatoriamente, um dos temas previamente delimitados, tudo isto baseado nos pressupostos da educação ambiental. Essa pesquisa será realizada com a leitura de artigos, entrevistas em órgãos públicos e empresas privadas, trabalhos e informações postadas na internet.

A avaliação do projeto: Este projeto é avaliado qualitativamente conforme o Projeto Político Pedagógico (P.P. P) da escola e recebe duas notas que somarão as demais notas do $2^{\circ}$ trimestre do ano letivo. A parte a ser entregue para o professor será avaliada em 0,5 pontos de um total de 3,0 pontos do trimestre, sendo que todos os componentes do grupo ganham a mesma nota que constará na capa do trabalho. A apresentação será avaliada em 0,5 pontos de um total de 3,0 pontos do trimestre, sendo que esta é uma nota pessoal e depende de cada apresentação, portanto, um mesmo grupo pode ter até quatro notas diferentes. Esta avaliação foi acordada com os alunos que entenderam que o professor não pode fiscalizar quem participou ou não do trabalho escrito, porem, pode avaliar independentemente cada apresentação.

\section{Meios oferecidos para o desenvolvimento do projeto.}

O Blog www.sites.google.com/site/aprmatematica foi criado, pelo autor, especialmente para que cada grupo tivesse um local de fácil acesso aonde encontrasse informações importantes 
para o desenvolvimento do projeto e que estivessem reunidas em um só ambiente. Neste blog cada grupo, ou aluno, poderá fazer downloads sobre metodologia de pesquisa científica, referencial teórico, exemplos de citações, modelo da capa e do rosto do projeto a ser entregue, ainda, exemplos de projetos prontos e exemplos da apresentação de alguns projetos. Ainda neste Blog foi fornecido ao aluno um compilado das normas da Associação Brasileira de Normas Técnicas (ABNT), para que o mesmo pudesse formatar seu projeto de pesquisa segundo o acordado entre 0 autor e os grupos. A escola, além da biblioteca e do acesso aos professores de todas as áreas, cedeu o espaço físico e o equipamento tecnológico para que o aluno pudesse usar as ferramentas de mídia para a apresentação deste projeto de pesquisa.

\section{REFERÊNCIAL TEÓRICO}

\section{Passivo Ambiental}

O passivo ambiental representa todas as obrigações contraídas de forma voluntária ou involuntária, que exigirão em um momento futuro entrega de ativos, prestação de serviços ou sacrifício de benefícios econômicos, em decorrências de transações ou operações passadas ou presentes, que envolveram a instituição com o meio ambiente e que acarretaram algum tipo de dano ambiental. Tão alto quanto os custos dos recursos físicos necessários para a reparação dos danos provocados, são os gastos requeridos para retração da imagem da empresa e/ou instituição e de seus produtos e serviços, especialmente, quando tais eventos são alvos da mídia e da atenção de ambientalistas e de organizações não governamentais (ONGs). A lei $n^{\circ} 9.921$, de 27 de julho de 1993 do Código Estadual do Meio Ambiente, que dispõe sobre a gestão dos resíduos sólidos, em seu art. $8^{\circ}$, relata que

A coleta, o transporte, o tratamento, o processamento e a destinação final dos resíduos sólidos de estabelecimentos industriais, comerciais e de Prestação de serviços, inclusive de saúde, são de responsabilidade da fonte geradora independentemente da contratação de terceiros, de direito público ou privado, para execução de uma ou mais dessas atividades. (BRASIL. 1993).

A constituição federal de 88, ao estabelecer as competências das esferas de governo, explicitou com mais clareza a responsabilidade dos municípios na prestação de alguns serviços, assim como para autuar em áreas específicas. Sem descrever na integra a lei, posso destacar o que diz a edição publicada pela Federação das Associações dos Municípios do RS (FAMURS, 2005, p.26): "Quanto às competências no trato das questões ambientais, podemos verificar que especial atenção é dedicada no art. 23 e 30 e o capítulo que inicia no art. 25".

A lei orçamentária do município é um instrumento legal que estima a receita e fixa as despesas do município. Dentre outras disposições devem ser observadas as que prevêem as despesas do serviço de limpeza pública, a que fixa os custos de obras e projetos de destinação de resíduos, a que fixa gastos com a formação e manutenção de consórcios intermunicipais e/ou convênios e a que prevê a cobrança de taxas de serviços para o licenciamento ambiental. 


\section{Gestão de Resíduos}

O tema da limpeza urbana está assumindo papel de destaque entre as demandas da sociedade brasileira e das comunidades locais. Muitas instituições governamentais ou não e a sociedade civil começam a se mobilizar para enfrentar o problema, por muito tempo, relegados a um segundo plano. A mídia está atenta, o ministério público e os órgãos ambientais atuam voltados especialmente na busca de soluções negociadas em relação à erradicação dos lixões e de possíveis passivos ambientais que veriam a causar danos significativos no passivo futuro de um município. Sancionada em agosto de 2010 e regulamentada em dezembro de 2010, a Política Nacional de Resíduos Sólidos (PNRS), sob forma da Lei $\mathrm{N}^{\circ} 12.305$, institui o princípio de responsabilidade compartilhada pelo ciclo de vida dos produtos, o que abrange fabricantes, importadores, distribuidores, comerciantes, consumidores e titulares dos serviços públicos de limpeza urbana e de manejo de resíduos sólidos. A emissão e a destinação de resíduos, fixa que os consumidores também devem atuar para que esta lei seja cumprida uma vez que a eles é devido o serviço de devolver este resíduo reutilizável e reciclável sempre que existir serviço de logística reversa ou coleta seletiva em seu município. Para classificar este serviço de logística reversa a Lei 12305, no CAPÍTULO II, das DEFINIÇÕES, em seu Artigo $3^{\circ}$ diz que

XII - logística reversa: instrumento de desenvolvimento econômico e social caracterizado por um conjunto de ações, procedimentos e meios destinados a viabilizar a coleta e a restituição dos resíduos sólidos ao setor empresarial, para reaproveitamento, em seu ciclo ou em outros ciclos produtivos, ou outra destinação final ambientalmente adequada (BRASIL. 2010).

O Código Estadual do Meio Ambiente, em seu art. 55 diz que a construção, instalação e operação de atividades potencialmente poluidoras ou capazes de causar degradação ambiental dependem de prévio licenciamento do órgão ambiental competente e, em seu art. 69 o Código Estadual do Meio Ambiente ressalta que: "Caberá aos municípios o licenciamento ambiental dos empreendimentos e atividades consideradas como de impacto local, bem como aquelas que the forem delegadas pelo Estado por instrumento legal ou convênio".

As instituições responsáveis pelos resíduos sólidos municipais e perigosos, no âmbito federal, estadual e municipal são determinadas através dos artigos 23 e 30 da constituição federal que diz, por exemplo, no inciso I e $\mathrm{V}$ do art. 30: "O município tem a atribuição de legislar sobre assuntos de interesse local, especialmente quanto à organização dos seus serviços públicos, como é o caso da limpeza urbana" (BRASIL. 1988). O município tem a competência para estabelecer o uso do solo em seu território. No âmbito empresarial é necessária a implantação de um sistema de gestão ambiental, a partir de elementos essenciais, tais como: política ambiental com metas e compromissos; planejamento do impacto ambiental de suas atividades; implementação e operação de ações para atingir metas; monitoramento e correção destas ações e revisão gerencial, que permite assegurar a adequação e o controle dos impactos ambientais de suas atividades. 0 manejo ambientalmente saudável dos resíduos deve ir além se simples deposição ou aproveitamento por métodos seguros. O gerenciamento dos resíduos sólidos deve ser dar pelo envolvimento dos diversos órgãos da administração pública e da sociedade civil, elevando assim a qualidade de vida da população. Já em 1985, José Lutzenberger, o mais destacado ambientalista que o Brasil conheceu, dizia que. 


\begin{abstract}
Devemos aprender a produzir menos lixo e a não misturar o que, separado, manteria um valor. Lixo não é outra coisa senão material bom no lugar errado. Na destinação de resíduos também podem ser encontradas soluções baratas, sociais e ecológicas. Começa a escassear dinheiro para fazer loucuras; talvez possamos então a começar a fazer coisas inteligentes - abrindo espaço para trabalho criativo de profissionais hoje ameaçados de desemprego (LUTZENBERGER. 2004. pg. 34).
\end{abstract}

\title{
Educação Ambiental
}

Em 1975, a Organização das Nações Unidas para a Educação, à Ciência e a cultura (UNESCO), em colaboração com o Programa das Nações Unidas para o Meio ambiente (PNUMA), em resposta à recomendação 96 da Conferência de Estocolmo, cria o Programa Internacional de Educação Ambiental (PIEA), destinado a promover, nos países-membros, a reflexão, a ação e a cooperação internacional nesse campo.

No Brasil, em 1973, cria-se a Secretaria Especial do Meio Ambiente (SEMA), e preocupa-se em definir seu papel no contexto nacional. A Política Nacional do Meio Ambiente, definida por meio da Lei no 6.938/81, situa a Educação Ambiental como um dos princípios que garantem "a preservação, melhoria e recuperação da qualidade ambiental propícia à vida, visando assegurar no país condições ao desenvolvimento socioeconômico, aos interesses da segurança nacional e à proteção da dignidade da vida humana" (BRASIL. 1981). Estabelece, ainda, que a Educação Ambiental deve ser oferecida em todos os níveis de ensino e em programas específicos direcionados para a comunidade. Visa, assim, à preparação de todo cidadão para uma participação na defesa do meio ambiente. O Decreto $n^{\circ} 8.351 / 83$, que regulamenta a Lei $n$. o 226/87 determina a necessidade da inclusão da Educação Ambiental, como um dos temas transversais, nos currículos escolares de 10 e 20 graus. Esse parecer recomenda a incorporação de temas ambientais da realidade local compatíveis com o desenvolvimento social e cognitivo da clientela e a integração escola-comunidade como estratégia de aprendizagem.

Na década de 1990, o Ministério da Educação (MEC), o Ministério do Meio Ambiente (MMA) e o Instituto Brasileiro do Meio Ambiente e dos Recursos Naturais Renováveis (IBAMA) desenvolvem diversas ações para consolidar a Educação Ambiental no Brasil. No MEC, são aprovados os novos "Parâmetros Curriculares Nacionais" (PCN's) (BRASIL, 1997) que incluem a Educação Ambiental como tema transversal em todas as disciplinas. Várias Organizações Estaduais do Meio Ambiente (OEMAs) implantam programas de Educação Ambiental e os municípios criam as secretarias municipais de meio ambiente, as quais, entre outras funções, desenvolvem atividades de Educação Ambiental.

A educação ambiental, portanto, não se trata de uma idéia, um mero conceito adotado por algumas pessoas e/ou grupos interessados em para melhorar o mundo, ela é regulamentada por leis federais, estaduais e municipais. A Educação Ambiental tornou-se lei sob o N 9.795/99, em 27 de abril de 1999. O Capítulo I, art. $2^{\circ}$ diz que: "A educação ambiental é um componente essencial e permanente da educação nacional, devendo estar presente, de forma articulada, em todos os níveis e modalidades do processo educativo, em caráter formal e não formal" (BRASIL. 1999). 
A escola, além de outros meios de comunicação é responsável pela educação do indivíduo e consequentemente da sociedade, uma vez que já o repasse de informações, isso gera um sistema dinâmico e abrangente a todos. Conforme relatado por Dias.

A educação Ambiental deverá desempenhar o importante e fundamental papel de promover e estimular a aderência das pessoas e da sociedade, como um todo, a esse novo paradigma. Aliás, este não seria o papel apenas da educação Ambiental, mas da educação como um todo. (DIAS, 2004, p. 94).

Atualmente é comum a contaminação dos cursos de água, poluição atmosférica, devastação de florestas e matas, a caça indiscriminada, o extermínio de espécimes da fauna e da flora, o recolhimento e o acondicionamento do lixo produzido pelo homem em locais impróprios, gerando danos, talvez irreversíveis ao meio ambiente. Dentro deste contexto, é clara a necessidade de mudar o comportamento do homem em relação à natureza, no sentido de promover sob um modelo de desenvolvimento sustentável a compatibilização de práticas econômicas e conservacionistas.. Utiliza-se como laboratório, o metabolismo urbano, rural e seus recursos naturais e físicos, iniciando pela escola, expandindo-se pela circunvizinhança e sucessivamente pela cidade, região, etc. A aprendizagem será mais efetiva se estiver adaptada às situações da vida real ou do meio em que vivem aluno e professor, tudo isso imbuído do lema: pensar globalmente, agir localmente. Para reforçar ainda essa posição da necessidade da comunidade escolar participar da Educação Ambiental com planejamento educacional, pode-se citar Paulo Freire, onde ele afirma que:

Todo planejamento educacional, para qualquer sociedade, tem que responder às marcas e aos valores dessa sociedade. Só assim é que pode funcionar o processo educativo, ora como força estabilizadora, ora como fator de mudança. Às vezes, preservando determinadas formas de cultura. Outras, interferindo no processo histórico, instrumentalmente. De qualquer modo, para ser autêntico, é necessário ao processo educativo que se ponha em relação de organicidade com a contextura da sociedade a que se aplica. (FREIRE, 2002, p.10).

\section{Temas transversais e áreas do conhecimento}

A definição de área de estudo evidencia a natureza dos conceitos tratados, definindo o corpo de conhecimentos e o objetivo da aprendizagem e situam o professor dentro de um conjunto definido e conceitualizado de conhecimentos que devem ser repassados aos alunos. Esse professor, considerando a multiplicidade de conhecimentos, pode e deve tomar decisões a respeito de suas intervenções e da maneira como trabalhará cada tema, de forma a proporcionar uma abordagem mais significativa e contextualizada. Atendendo a essas perspectivas, um conjunto de temas: ética; saúde; meio ambiente; pluralidade cultural e orientação sexual, eleitos por envolverem problemáticas sociais, são integradas na proposta educacional dos PCN's como Temas Transversais e, pressupõe um tratamento integrado das áreas e de um compromisso das relações sociais e pessoais. Os Temas Transversais não constituem novas áreas do conhecimento, eles podem ser definidos como conteúdos de orientações didáticas no decorrer de toda a escolaridade. Um dos pilares de trabalho dos Temas Transversais é através de projetos que 
integrem diversas disciplinas e que supõe a realização de algo que não existe e que é realizável. Trabalhar com projetos representa o fim da passividade em favor da interação aluno/professor/escola/comunidade e realidade. Freire (p. 32) já dizia: pesquiso para conhecer o que ainda não conheço e comunicar ou anunciar a novidade. O Professor não abandona o conteúdo tradicional para trabalhar um tema transversal. Ele deve estabelecer relações entre ambos e deve induzir o aluno a usar o conhecimento adquirido na sua área para trabalhar, analisar e quantificar este tema.

\section{RESULTADOS E DISCUSSÕES}

Efetuar a pesquisa sobre leis e normas encaminhou a descoberta da realidade sócioambiental do município, que foi feita através de visita ao órgão municipal responsável, Secretaria Municipal do Meio Ambiente e a uma longa entrevista com o responsável pelo setor. O diagnóstico inicial permitiu o aprofundamento sobre leis que instituem e regulamentam o meio ambiente como um todo e sobre os órgãos federais, estaduais e municipais que se voltam para o trato deste tema. O conhecimento adquirido sobre educação ambiental e passivo ambiental adquirido pelo autor foi repassado aos alunos com a finalidade que estes, a partir destas informações, desenvolvessem o projeto de pesquisa relacionando conteúdos matemáticos estudados em sala de aula, o tema transversal meio ambiente e conteúdos de áreas relacionadas com este tema, como biologia, química, física, sociologia, filosofia, etc. Este projeto é avaliação correspondente a uma das notas relativas ao $2^{\circ}$ trimestre do ano letivo com a finalidade de mensurar a realidade e repassar esta informação ao público que assistirá a apresentação do trabalho proposto.

\section{Resultados da criação do Blog}

A ferramenta Blog, criada para ser um acessório de ajuda a ser usada pelo aluno durante a realização do projeto, mostrou-se de tamanha importância que ficou incorporado no linguajar e nas conversas diárias sobre o projeto. As informações contidas no blog foram muito úteis no desenvolver do projeto, visto que o aluno, embora concluinte do ensino médio, jamais havia realizado um trabalho de tal envergadura. Paulo Freire, em seu livro Pedagogia da autonomia, destaca: "como professor, não me é possível ajudar o educando a superar sua ignorância se não supero permanentemente a minha" (FREIRE, 1996, p.95). Outros professores da escola que desenvolvem projetos semelhantes solicitam que seus alunos usem este endereço eletrônico para que seus alunos coloquem os trabalhos nestas mesmas normas.

\section{Resultados das pesquisas realizadas pelos alunos e apresentações dos trabalhos.}


A pesquisa desenvolvida por cada um dos grupos o levou a olhar seu país sob um foco ambiental e permitiu que o mesmo olhasse sua realidade com lupa, pois o aluno viu problemas que antes the eram despercebido. Embora tenham surgidos em torno de trinta (30) grupos e muitos destes tenham trabalhados temas iguais, pode-se perceber um enfoque diferenciado, pois, cada grupo imprimiu sua visão de realidade, o que distanciou a linha de escolha do foco em cada um dos grupos. Segue, agora, alguns dos títulos escolhidos pelos grupos:

Meio Ambiente e o ser humano;

Energia Hidrelétrica - O projeto e as conseqüências;

Comunidades Quilombolas;

Gestão de Resíduos sólidos;

Química e Biologia: Passivo Ambiental;

Lixo Hospitalar;

Gestão Ambiental: Ética do Desmatamento;

Meio Ambiente em Risco;

Hidrelétrica: Hidrelétrica de Belo Monte;

Constituição, Regulamentação das Leis Ambientais e poluição do meio Ambiente;

Resíduos de serviços de saúde;

Impactos ambientais;

Abaixo são mostradas algumas figuras que fizeram parte das apresentações do projeto de pesquisa realizado pelos alunos e alguns folders recolhidos junto à administração pública municipal e representam ações sócio-ambientais realizadas no município e nos consórcios inter municipais que o município se envolve, tendo como temática o meio ambiente e as ações tomadas em favor deste.

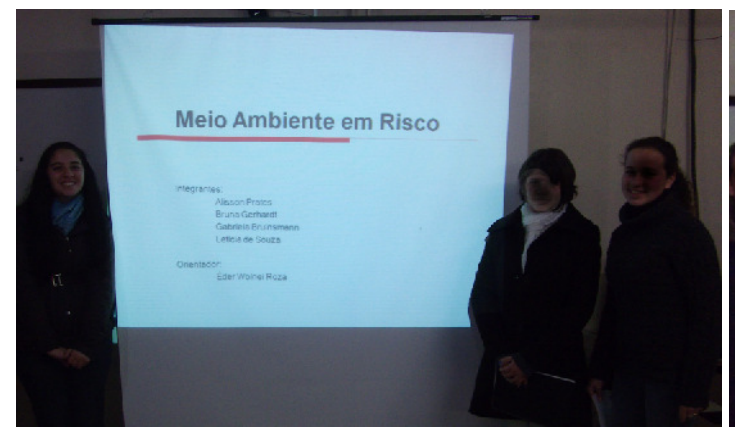

Figura 1a - apresentação do trabalho "Meio Ambiente em risco".

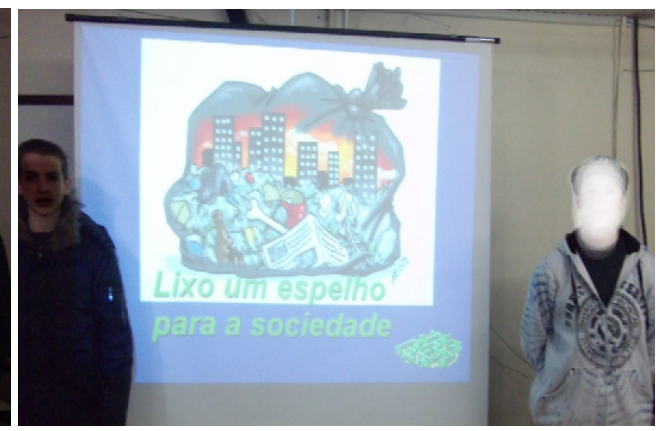

Figura 1 b - apresentação do trabalho "Lixo um espelho para a sociedade". Fonte: autor 

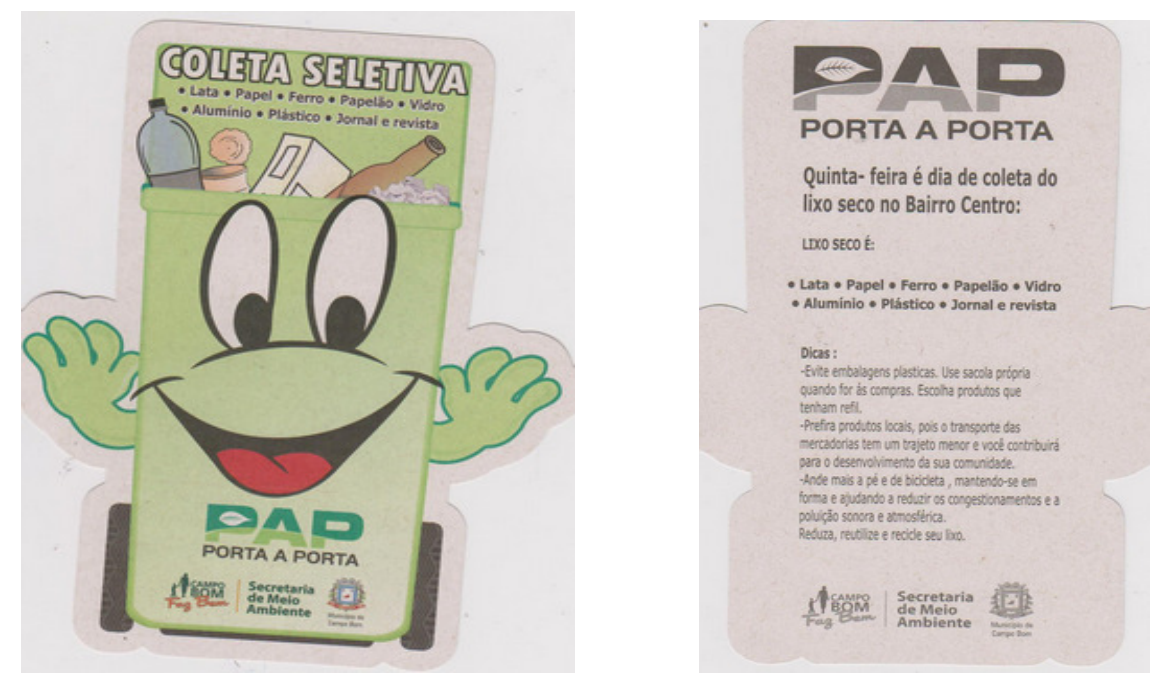

Figura 3 - Folders da coleta seletiva (frente e verso). Fonte: Prefeitura Municipal

\section{CONCLUSÃO}

Percebe-se ao longo dos anos que as questões ambientais, que pouco entram na sala de aula, principalmente no estudo da matemática, estão presentes em nossa realidade e devem ser trabalhadas em forma que questionamentos, situações-problemas, perguntas e respostas. Esta atitude foi motivada pela intenção de estabelecer um compromisso pela identificação de necessidades comunitárias, conhecimento da qualidade de vida oferecida pela administração pública e órgãos privados e ao exercício da cidadania de cada um dos alunos (as) envolvidos (as).

Muitos alunos chegam, ao final do ensino médio, despreparados e demoram a absorver esta nova realidade em que Ihes é cobrado uma participação social e política na sua realidade. Tomando consciência disto, e sabendo que é dever do professor formar e reformar o que é formado. Sabendo que o aluno não é sujeito que recebe o conhecimento pronto, foi que se propôs este projeto transversal entre meio ambiente e a matemática.

Usar um tema transversal, como o meio ambiente e a matemática, para aproximar o aluno de seu cotidiano fazendo-o olhar para grandes temas que o rodeiam, como a sua produção de lixo ou a produção do lixo na sua cidade é levá-lo a uma relação interpessoal que o conduza a sua descoberta como cidadão, como ser total, inteligente e capaz de seus próprios juízos de valor. 0 resultado, aliás, foi amplamente satisfatório, pois, todos os trabalhos se adequaram as normas propostas, tanto na realização de pesquisas em sua realidade quanto no uso de normas técnicas na digitação do trabalho. O aluno construiu este saber e se encontra pronto para começar qualquer trabalho proposto, seja no ensino médio seja em um curso superior, respeitando as implicações inerentes a cada proposta e sua realidade. 


\section{REFERÊNCIAS BIBLIOGRÁFICAS}

ARMANI, Domingos. Como Elaborar Projetos? Guia Prático para a Elaboração e Gestão de Projetos Sociais. Porto Alegre: Tomo Editorial, 2000.

DIAS, Genebaldo Freire. Educação Ambiental: Princípios e práticas. 9ạ ed. São Paulo - Gaia, 2004. DEMO, Pedro. Avaliação e democracia. Artigo encartado na revista $A B C$ Educatio - ano 7, $n^{\circ} 56$, maio de 2006.

FAMURS. Gestão Pública Municipal. Orientações nas ações municipais no meio ambiente. Planejamento integrado, estratégico e sustentado. Coletânea básica de legislação ambiental. RGS, 2005.

FREIRE, Paulo. Política e Educação: ensaios / Paulo Freire. - 5. ed. - São Paulo, Cortez, 2001. (Coleção Questões da nossa época; v.23).

FREIRE, Paulo. Pedagogia da autonomia: Saberes necessários à prática educativa / Paulo Freire. São Paulo: Paz e Terra, 1996 (Coleção leitura).

LUTZENBERGER, José: Manual de ecologia: do jardim ao poder: Vol. I, Porto Alegre: L\&PM, 2004. PARÂMETROS CURRICULARES DO ENSISNO MÉDIO. Ensino Médio. 2000. Disponível em: <http://portal.mec.gov.br/seb/arquivos/pdf/blegais.pdf. Acesso em 22 Mar. 2011.

PRESIDÊNCIA DA REPÚBLICA. Casa Civil. Subchefia para Assuntos Jurídicos. Lei $n^{\circ} 12.305$, de 02 agosto de 2010.2 Disponível em: <http://www.mma.gov.br/port/conama/legiabre.cfm?codlegi=636>. Acesso em 22 Ago.2010.

PRESIDÊNCIA DA REPÚBLICA. Casa Civil. Subchefia para Assuntos Jurídicos. Constituição da República Federativa do Brasil de 1988. Disponível em; <http://www. planalto.gov.br/ccivil 03/constituicao/constitui\%C3\%A7ao.htm>. Acesso em 22 Set. 2010.

RIO GRANDE DO SUL. Assembléia Legislativa do Estado. Código Estadual da Meio Ambiente. Comissão de Saúde e Meio Ambiente. Grupo de Trabalho. Agosto, 2000.

SANTOS, A. R. dos. Metodologia Científica: a construção do conhecimento. Rio de Janeiro: DP\&A, 1999. 